\title{
Pensioners mean problems
}

\section{Modern governments have in common an obsession with getting pensioners off the backs of those still} at work. They are in danger of ignoring the link with employment and of forgetting equity.

How, in the long run, can a modern state hope to deal equitably with its pensioners, especially if a substantial fraction of its putatively working population is forced into premature pensionhood by unemployment? And what if the social burden of the unemployment rolls will in any case be made permanent by developments in technology, especially by the prospect that the automation of production processes, after three decades of enthusiastic talk, is about to become a reality? These questions have been in the air for the past decade. They have become more urgent as the economic recession has been prolonged, and as some people have begun to suspect that economic recovery may, on this occasion, be marked by continuing stagnation of employment and thus by an unpalatable choice - either higher taxes or a widening of the gulf between those at work and those without jobs (pensioners included).

The question is far from being academic. For the past four years, a British government elected originally on the promise that it would reduce taxes across the board, and reinvigorate the economy by making it competitive, has seen social services consume a growing proportion of its budget and unemployment remain obdurately high (more than three million) in spite of flickering signs that economic activity is picking up. Demography offers no relief. The number of voluntary pensioners is certain to increase, the number of involuntary pensioners may remain large. Mrs Margaret Thatcher, the Prime Minister, has taken to pointing to the simple arithmetic of this set of circumstances - that consumption by pensioners can be financed only at the expense of those still at work, either by means of taxes or by that part of people's savings that does not find its way into capital investment. Mr Norman Fowler, Secretary of State for Health and Social Security, has gone further, putting himself at the head of a commission to look into the way in which state pensions in the United Kingdom should in future be financed. There are several interlocking issues, some practical and urgent (such as making sure that occupational pensions schemes do not inhibit mobility), some more distant but even more important. The success of $\mathrm{Mr}$ Fowler's inquiry will, however, depend crucially on the assumptions on which is is founded.

The first principle should be equitability. In most industrialized societies, people are compelled by law to contribute to pensions schemes separately from general taxation, presumably on the grounds that this simulates what happens when people contribute to private pensions schemes. Present consumption is forgone, postponed until after retirement. Governments are usually pleased with this arrangement, which is good for what is called their cash flow, but are less happy with the implied commitment to future pensioners. In some places, the United States for example, contributions are formally earmarked for the eventual purpose of paying pensions, but then promptly used to reduce the government's general need to borrow. Moreover, the existence of an earmarked fund does not absolve the government from the need to step in to top it up if it should seem deficient, so that the end effect is the same as in the British system. People pay an extra pension tax while they are at work and have the illusion that this "entitles" them to a pension but in retirement are paid as pension only what the government of the day decides it can afford.

In Britain, it was held to be a famous victory for the House of Commons that, some years ago, two private members were able to amend the finance bill so as to link state pensions with the cost of living, but that is plainly unfair to pensioners if general prosperity is increasing. Worse still, however, is the general assumption by those who manage the government's business that pensions are an unmitigated drain on national resources, morally indistinguishable from a kind of poor relief. That might be so if it were not for the promise during pensioners' working lives that pensions would be payable. If Britain's Norman Fowler is looking for an equitable escape from present pensions problems, he might think of working towards a restriction of the numbers entitled to some kind of state pension, an offsetting reduction of what people pay - and then waiting until existing promises have been required before reaping the financial benefits.

Demography suggests another fruitful avenue for exploration. The post-war baby boom of the 1950s implies that the numbers of pensioners will be growing rapidly in the early decades of the next century, both in absolute numbers and as a fraction of the population in industrialized countries. Yet in most places, governments have not seriously tackled the problem of how best to encourage policies of flexibility on retirement. Throughout Western Europe, rigid definitions of retirement age still apply, taking no account of either increased longevity or changed social patterns, especially the growth of the female working population. (Japan and West Germany are two exceptions.) But the financial benefits to governments of flexibility are potentially huge - potential pensioners may remain productive. How great the benefits may soon become apparent in the United States, where discrimination on the grounds of old age is now illegal.

But will not a public policy that allows people to remain at work when they might retire merely exacerbate the problem of unemployment, itself almost intractable? This question begs that of whether technological developments now in prospect indeed entail the awesome consequences commonly attributed to them, factories run by robots and offices staffed by computing machinery, and with no jobs for the less skilled majority of any nation. Curiously enough, even those plotting these great technological upheavals are often among the first to beat their breasts and proclaim that they are awed by the enormity of what they are about. The truth, however, is that the present upheaval of technology in industrialized communities is a sign of yet another redistribution of labour in the sense in which Adam Smith intended the term. Some years hence, it will be found that some countries have entirely changed the pattern of their production. Some will have abandoned steel, or shipbuilding, for computer manufacture. Others will have stayed in the traditional industries. All will need agriculture, although policies of self-sufficiency will not be nearly justifiable as in the past. There is nothing new about this process (witness the 1870s). The outcome, invariably, is not merely a redistribution of labour between countries but a repartitioning of wealth as well. What matters most, to would-be pensioners, is that the economies on which they will ultimately depend should be among the stronger, which in turn argues for a transfer from public to private saving and for spending a greater proportion of private savings on capital investment. But how can a minister of pensions hope to tackle such important strategic questions, more properly the preserve of chancellors of the exchequer? Mr Fowler, in short, has taken on a gigantic task. Is he, by any chance, ambitious? 